\title{
EXTRAORAL AND ORAL SIGNS IN TWO PATIENTS WITH STURGE-WEBER SYNDROME - CASE REPORT AND REVIEW OF THE LITERATURE
}

\author{
Assya Krasteva \\ Department of Oral and Imaging diagnostics, Faculty of Dental Medicine, \\ Medical University of Sofia
}

\begin{abstract}
INTRODUCTION: Sturge-Weber syndrome is a rather uncommon congenital condition that occurs sporadically, characterized by the combination of ipsilateral angiomatous lesions of the face, oral soft tissues, and jaws with venous angioma of the leptomeninges over the cerebral cortex. However, the main clinical features of this syndrome are facial vascular cutaneous naevus, usually unilateral, which often follows the outline distribution of the trigeminal nerve.

MATERIAL AND METHODS: We report two cases of 7-year-old and 11-year-old girls with diagnosis Sturge-Weber syndrome, emphasizing the oral and extraoral manifestation related to the syndrome. The patients were presented with a cutaneous vascular nevus on the face during early childhood as well as epileptic crisis episodes, with no ophthalmic alterations.

CONCLUSION: Sturge-Weber syndrome commonly affects the oral cavity therefore, it is important for the dentists' knowledge in order to provide an adequate dental management without complications.
\end{abstract}

Keywords: Sturge-Weber syndrome, oral cavity, dental treatment

\section{INTRODUCTION}

Sturge-Weber syndrome (SWS) or Encephalotrigeminal angiomatosis belongs to a group of disorders collectively known as phakomatoses ("motherspot" diseases). It consists of congenital hamartomatous malformations that may affect the eye, skin and

Address for correspondence:

Assya Krasteva-Panova

Department of Oral Imaging and Oral Diagnostic

Faculty of Dental Medicine

Medical University of Sofia

1 Georgi Sofiyski blvd.

1431 Sofia, Bulgaria

phone: +359887875496

e-mail: asyakrasteva@abv.bg

Received: December 7, 2014

Accepted: December 19, 2014 central nervous system at different times (11). The syndrome is presented as angioma of the leptomeninges extending to the cerebral cortex with ipsilateral angiomatous lesions, unilateral facial nevus affecting a division of the trigeminal nerve, hemiparesis, intracranial calcification, mental retardation, glaucoma and refractory epilepsy $(4,5)$.

ORAL ANDEXTRAORAL MANIFESTATION

The most apparent extraoral indication of SWS is a facial birthmark or "port-wine stain" present at birth and typically involving at least one upper eyelid and the forehead $(1,5,9)$.

The port-wine nevus, localized especially over the right side on the face, is detected in 87 to $90 \%$ of the cases (10). Bilateral involvement can be detected in about $33 \%$ of the cases and extension of the lesion over the middle line is observed in $50 \%$ of the pa- 
tients. In SWS, one of the prevalent radiologic findings is thickening of the skull cap (10).

Oral manifestations occur in about $40 \%$ of patients and are represented by the gingival hyperplasia (vascular type) usually restricted to the ipsilateral maxilla or mandible, bleeding problems for extractions, more advanced eruption of teeth on the affected side than on unaffected side, angiomatosis involving buccal mucosa, mouth's floor, lips, palate, tongue and jugal mucosa, morphological and histological alterations in the periodontal tissues, pulp, macrocheila (large lips, due to the angiomatosis on the lips), hemihypertrophy of tongue, changes in alveolar process, unilateral malocclusion (gingival involvement can vary from light vascular hyperplasia to monstrous overgrowth making closure almost impossible). The radiological finding may indicate bone destruction, furcation involvement, irregular bone trabecular pattern and loss of lamina dura over teeth present in affected areas $(1,4,5,9,13)$.

\section{ORAL HEALTH STATUS}

Early eruption of teeth from increased vascularity, periodontal and oral hygiene problems are reported (4).

\section{CASE HISTORY}

We reported two cases of 7-year-old and 11-yearold girls with a diagnosis Sturge-Weber syndrome, emphasizing the oral and extraoral manifestation related to the syndrome. The patients were referred to the Faculty of Dental Medicine, Department of Oral and Imaging Diagnostics, required dental care and were consulted about their oral health. A dermatologist was consultated.

\section{Case one - a 7-year-old girl}

Extra oral examination of a 7-year-old girl revealed that the port-wine stain had unilateral distribution affecting V1 and V2 distribution on the left side of face. It extended from the middle of the forehead and involved the eye, half of the nose, cheek, philtrum, and left side of the upper lip and maxilla. The lower lip and lower jaw were not involved (Fig. 1 and Fig. 2).

The overgrowth gingiva on the left side of maxilla appeared inflammed, reddened with a tendency of bleeding on probing (Fig. 2), while on the right side the gingiva appeared to be with normal color and consistency.

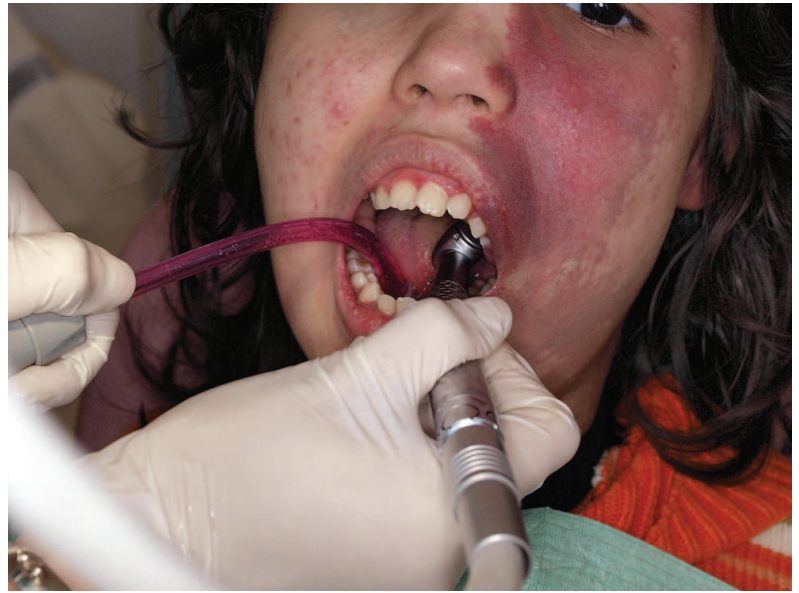

Fig. 1. Portwine stains on the left side of face

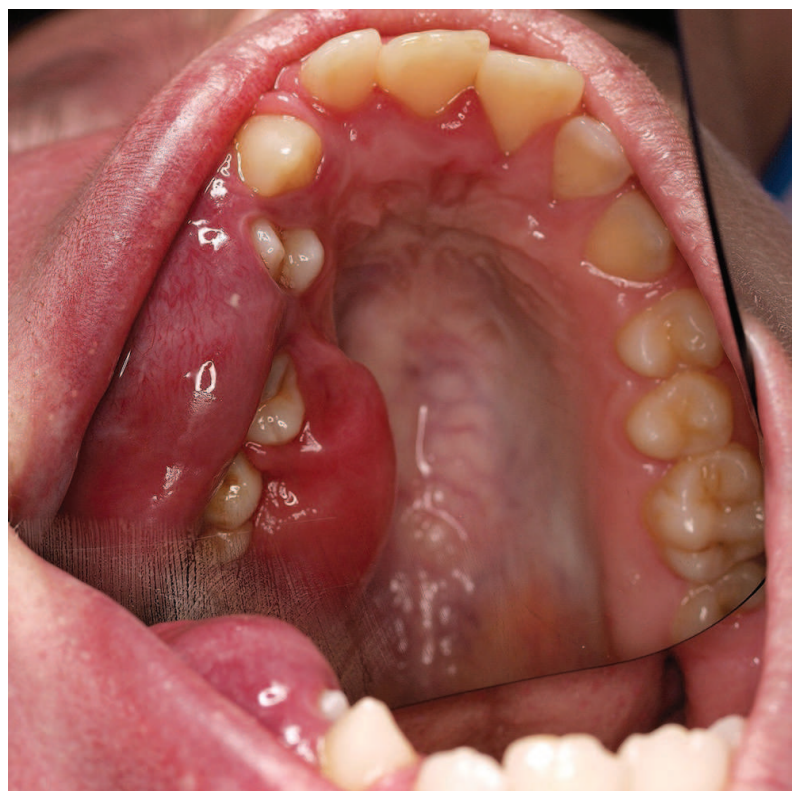

Fig. 2. Unilateral (left) port wine stains on the palate

The patient had permanent dentition, poor oral hygiene with extensive amount of plaque and bleeding on probing on the left and rigth side of dentition and malocclusion.

A thorough plaque control regimen was prescribed to minimize gingival inflammation which included oral prophylaxis at regular intervals, oral hygiene instructions (for regular brushing - two times daily for 3 minutes and use of chlorhexidine mouth rinse for 2 weeks, after that the recommendation was to use a herbal mouthwash). We treated dental caries in the 16 and 36 teeth, thanks to the positive attitude of the patient to the dental treatments despite the present mental problems. 
Extraoral and oral signs in two patients with Sturge-Weber syndrome - case report and review of the literature

\section{Case two - a 11-year-old girl}

In this case the extraoral examination revealed a bilateral facial vascular nevus (port-wine stains) on the left and right side of face extending V1 and V2 (Fig. 3).

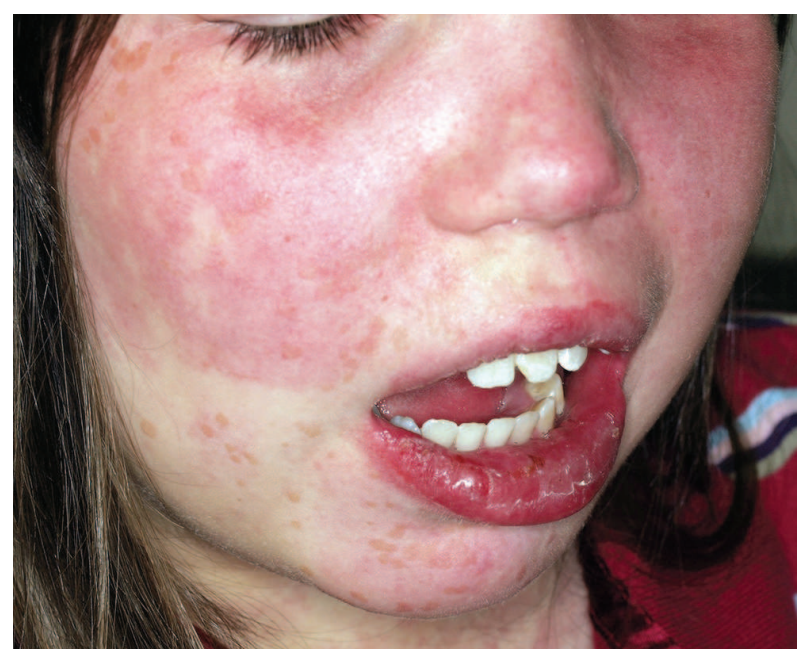

Fig. 3. Port wine stains on the left and right side of face extending V1 and V2.

On the other hand, intraoral examination revealed an angiomatous swelling only in the left gingiva on the maxilla and mandibular which bled on probing (Fig. 4).

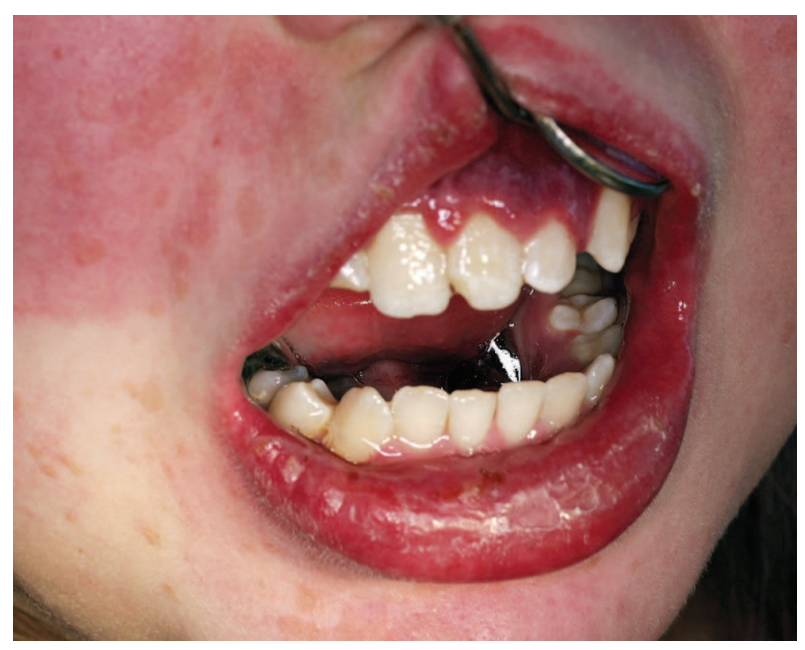

Fig. 4. Intraoral manifestation - an angiomatous swelling only in the left gingiva on the maxilla and mandibular.

In this patient, we were unable to perform dental examination due to lack of collaboration and psy- chiatric disorders. Our recommendations were for dental treatment of dental caries under general anesthesia and guidelines for maintaining good gingival and periodontal health.

\section{DISCUSSION}

The Sturge-Weber Syndrome was initially described by Schirmer in 1860 and was later specified by Sturge (1878), who associated the dermatological and ophthalmic changes to the disease's neurological manifestations. In 1992 Weber complemented it through the documentation of these patients' cerebral radiologic alterations (2).

The SWS presents with neurological, cutaneous, ocular and oral manifestations that may (or not) be associated with one another; however the most evident clinical manifestation is the presence of the nevus flammeus or port-wine stain on the face, which normally follows the course of branches V1 and V2 of the trigeminal nerve $(3,7)$.

Although its etiology is unknown, some authors say it is from a congenital malformation resulting from changes in the ectoderm, mesoderm and neural crest derivates (12).

Seizures and neurological deterioration typically develop in the first year of life rather than in adulthood and rarely after the third decade (7).

Fortunately, our patients did not have eye problems, but epileptic seizures and mental changes were present.

SWS diagnosis is established usually by portwine stains (which are the most frequent finding of the disease, generally present since birth, affecting half of the face and may expand to the neck with a characteristic to darken with age, ranging from reddish, in the beginning, to purple) followed by other signs, such as glaucoma, epilepsy, and mental retardation $(4,12)$.

According to I. Cigdem (1999) the port-wine nevus is localized on the face, especially over the right side ( 87 to $90 \%$ of the cases); in $50 \%$ of the patients the lesion extension is over the middle line and bilateral involvement can be detected in 33\% of the cases (3).

In our 7-year-old girl nevus flammeus is present only on the left side of the face without extension over the middle line. We detected ipsilateral gingival 


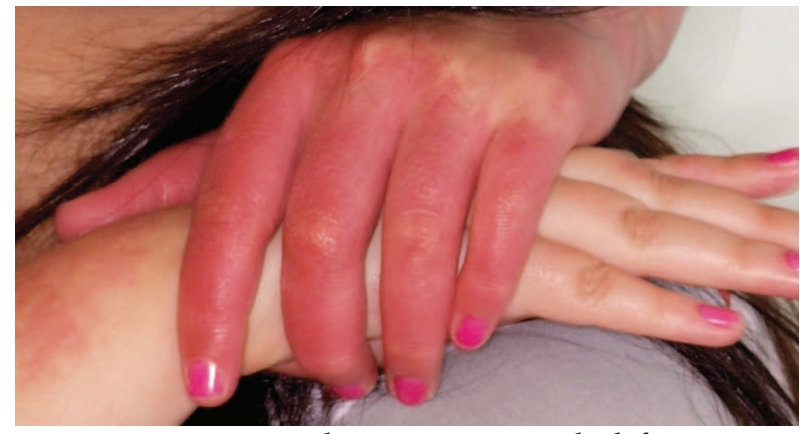

Fig. 5. Port wine hemangiomas on the left arm

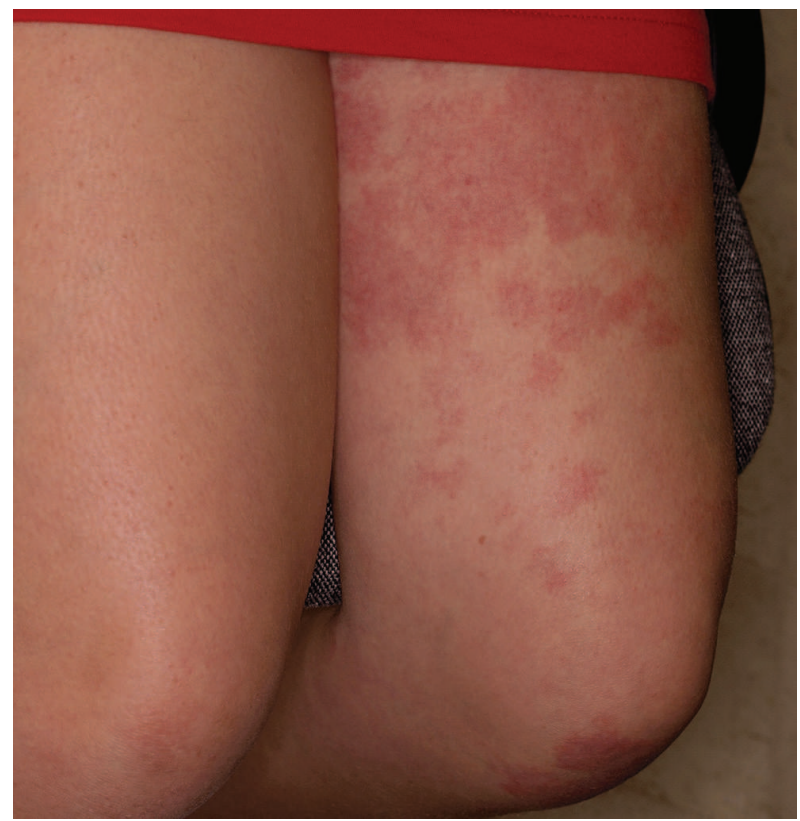

Fig. 6. Port wine hemangiomas on the left leg.

hyperplasia, characterized by an increase in the vascular component and gingival hemorrhage at minimal traumatisms and it is important to be noted that poor oral hygiene may intensify inflammation and gingival hyperplasia.

While in the 11-year-old girl the port-wine hemangiomas were present bilateral of the face and additional were detected also on the left left leg and arm (Fig. 5 and Fig. 6).

\section{GENERAL MANAGEMENT}

Treatment and prognosis depend on the nature and severity of clinical features. The general management of the patient includes control of epilepsy and ocular lesions. Presence of port-wine stains on the face can be a cosmetic problem and usually cause deep psychological trauma to the patient and the development of personality is affected in almost all patients (11). Port-wine stains can be treated by dermabrasion, tattooing, flash lamp pulsed tunable dye laser therapy, which can result in partial or complete clearing of the port-wine stains. A high dose of hydrocortisone given orally in infancy results in regression of well-localised small lesions (5).

DIFFICULTIES IN DENTAL MANAGEMENT

It is important that the dentist knows this disease's clinical features and complications that may occur. The dental rehabilitation of such patients is a complex process, requiring conservative management and may demand the use of behavior management techniques due to mental retardation. A major problem is hemorrhage from the angiomas, therefore surgical procedures in SWS should be conducted carefully due to increased risk of hemorrhage, even if they are considered as simple (4). The use of Nd:YAG laser for surgery provides the advantage of immediate hemostasis, minimal damage to surrounding tissues and no postoperative pain. Combination of gingivectomy and lasers can be used if the overgrowth is very large. To prevent reoccurrence, maintenance of good oral hygiene is very important even after gingivectomy (8).

Hospitalization with complete workup is recommended and oral intubation for general anesthesia is necessary. The patients with oral changes must be submitted to periodic oral check-ups.

\section{CONCLUSION}

The oral manifestations of Sturge-Weber patients require a good knowledge of this syndrome from the dental practitioners as well as knowledge of the best treatment to be performed due to increased risk of hemorrhage. The correct approach in these children is to include a multidisciplinary team to perform proper treatment and preventive following-up of these patients (a dental hygienist, dentist with pediatric knowledge, dental surgeon and oral pathologist).

\section{REFERENCES}

1. Ahluwalia TP, J Lata, P Kanwa. Sturge Weber syndrome with intraoral manifestations. A case report. Indian J Dent Res, 1998; 9(4):140-144.

2. Bhansali RS, RK Yeltiwar, AA Agrawal. Periodontal management of gingival enlargement 
associated with Sturge-Weber syndrome. J

Periodontol, 2008;79(3):549-55.

3. Cigdem İ, J Marcus. Sturge-Weber syndrome: report of an unusual cutaneous distribution. Brain Develop, 1999;21:68-70.

4. da Conceição JG, LFG dos Santos, TP de Sá Bahia, V de Silva, MEB Ramos, M Israel. Sturge-Weber syndrome: a case report. RSBO Revista SulBrasileira de Odontologia, 2011;8 (4): 469-472.

5. Godge P, S Sharma, M Yadav, P Patil, S Kulkarni. Sturge Weber syndrome: A case report. Rev Odonto Cienc, 2011;26(4):366-369.

6. Huang JS, CC Chen, YM Wu. Periodontal Manifestations and Treatment of Sturge-Weber Syndrome- report of two cases. Kao J Med Sci, 1997;3:127-135.

7. Hussain MS, DJ Emery, JR Lewis, WS Johnston. Sturge-Weber syndrome diagnosed in a 45-yearold man. CMAJ, 2004;170(11):1672.

8. Inchingolo F, M Tatullo, FM Abenavoli, $M$ Marrelli, AD Inchingolo, AM Inchingolo, G Dipalma. Comparison between traditional surgery, $\mathrm{CO} 2$ and Nd:Yag laser treatment for generalized gingival hyperplasia in Sturge-Weber syndrome: a retrospective study Journal of Investigative and Clinical Dentistry 2010;1(2): 85-89.

9. Khambete N, M Risbud, A Kshar. Sturge-Weber Syndrome: A Case Report. International Journal Of Dental Clinics, 2011; 3(1):79-81.

10. Lin DD, P Gailloud, EF McCarthy, AM Comi. Oromaxillofacial Osseous Abnormality in SturgeWeber Syndrome: Case Report and Review of the Literature AJNR Am J Neuroradiol, 2006;27(2):274-277.

11. Namrata C, G Bhaskar, N Bhaskar. Sturge - Weber syndrome: A case report. Contemp Clin Dent, 2010;1(3):183-185.

12. Neto FXP, MAV Junior, LS Ximenes, CCS Jacob, AGR Junior, CP Palheta, et al. Clinical Features of Sturge-Weber Syndrome. Int. Arch. Otorhinolaryngol., 2008;12(4):565-570.

13. Sen Y, E Dilber, E Odemis, A Ahmetoglu, FM Aynaci. Sturge Weber syndrome in a 14-yearold girl without facial naevus. Eur J Pediatr, 2002;161(9):505-506. 